\title{
Degree of Disease Acceptance and Health Seeking Behaviors for Type 2 Diabetic Patients at Diabetic Center in Hilla City
}

\author{
Mohammed Malih Radhi \\ M.Sc. Community Health Nursing, Kut Technical Institute, Middle Technical University, Iraq
}

\begin{abstract}
Diabetes is a disease that is expressed in life style diseases such as high blood pressure. Many of these diseases are the result of the behavior of the wrong.

Objectives: The study aims at identify the degree of disease acceptance patients and their health seeking behaviors; and determine the relationship between degree of acceptance and health seeking among patients.

Methodology: A descriptive study has been conducted by "purposive sample" accounts of 150 patients who review the diabetic center in Hilla City. Through the use of the questionnaire and interview techniques the data were collected and analyzed disruptively and inferentially.

Results: Findings depicts that most of the study sample aged (30-39) years old, (56.7\%) male, (45.3\%) married, (40\%) unemployed, and (52\%) notable read and write. The majority of $(48 \%$ and $44.7 \%)$ were never have accepted their disease and seek towards health respectively. There were a significant relationship between the degree of disease acceptance and seeking of health behavior at $p$-value $<0.05$.

Conclusion: Patients who diagnosed with type 2 diabetes and who review the diabetic center were never accepted their disease and never seek health. The accepted of disease were affected the seek towards health. Study that can be supported by a qualitative work using the clinical methodology with its tools and methods such as case study, clinical interview and psychological tests to achieve satisfactory acceptance and high self-control..
\end{abstract}

Keyword: Acceptance, Health Seeking, Type 2 Diabetic, Patients.

\section{Introduction}

Health has become a vocabulary that characterizes prosperous life and its direct and strong impact on various aspects of life (production, consumption, lifestyle, education, political programs ...) made it a strong indicator of the degree of development of a society alone ${ }^{1}$. Health does not mean idealism. It can be said that health exists when a person is able to build social relationships effectively, is able to reconcile and integrate with members of his community and when he can adapt his private life to the complex and diverse circumstances of the ocean ${ }^{2}$. In addition, individual selfdetermination and balancing of its biological, genetic, physical and psychological potentials. Health is the integration and balance of these aspects. In the case of the disease begins to recognize the individual threat, acute disease is the threat once and then the body returns to normal, but in the case of chronic illness is to live with the physical threat continues and physical restrictions continue $^{3}$. In order to achieve a behavioral application of health during daily practices, it is necessary to start from health concepts that contribute to the development of health awareness during education or health education to reduce health problems and limit their development ${ }^{4}$.

Education contributes effectively to the adoption of the concept of health in the community in general, which teaches the individual how to protect himself from diseases or prevent their development and avoid complications, through the acquisition of information related to health and the development of positive attitudes towards personal health and the health of others and modify unhealthy behavior ${ }^{5}$. The aim of health 
seeking is to instill healthy concepts and habits among individuals in order to ensure that they are followed by understanding, conviction, awareness and awareness, so that they become a way of life practiced by members of the whole society and all categories ${ }^{\mathbf{6}}$.

Since diabetes is one of the most prevalent chronic non-communicable diseases in the world, the number of infected people is increasing and the condition of patients is developing rapidly with the change of lifestyle. Most important and most dangerous is that most people are unaware of this disease and discover only by chance, most of them are of the type 2 diabetic, and this is due to the lack of health information and health awareness of the individual.

\section{Methodology}

It was conducted descriptive study to determine the degree of acceptance of patients with the disease and seek of health behavior. Also, to determine the relationship between the degree of acceptance and the seek of health among patients.

A "purposive sample" is selected by probability sampling approach accounts of 150 patients who review the diabetic center in Hilla City. Through the use of the questionnaire and interview techniques the data collected. The questionnaire involved the following part:

Part I: Degree of disease acceptance which composed of (28) items.

Part II: Health seeking behaviors which composed of (21) items.

It is determined by the reliability of internal consistency of the questionnaire to study half division method. Choose a convenient sample of 15 subject for the purpose of the reliability of the questionnaires. The Cronbach alpha correlation coefficient was calculated for such reliability. The results indicate that the correlation coefficient is $(\mathrm{p}=0.81)$ questionnaire to the degree of acceptance of the disease and $(p=0.89)$ questionnaire behaviors search for health, it is suitable for basic phenomenon in the study measures.

Data is analyzed by applying descriptive statistical data analysis approach, which includes frequency and percentage and average overall grade; and chi square as deductive.

\section{Results}

Table 1: Sample Characteristics

\begin{tabular}{|l|l|c|c|}
\hline General Information & Rating & Number & Percent \\
\hline \multirow{5}{*}{ Patients age } & $<20$ yer & 16 & 10.7 \\
\cline { 2 - 4 } & $20-29$ yer & 41 & 27.3 \\
\cline { 2 - 4 } & $30-39$ yer & 56 & 37.3 \\
\cline { 2 - 4 } & $40-49$ yer & 6 & 4.0 \\
\cline { 2 - 4 } & $50-59$ yer & 14 & 9.3 \\
\cline { 2 - 4 } & $60+$ yer & 17 & 11.3 \\
\hline \multirow{5}{*}{ Patients Gender } & Male & 85 & 56.7 \\
\cline { 2 - 4 } & Female & 65 & 43.3 \\
\hline \multirow{5}{*}{ Patients marital status } & Single & 66 & 44.0 \\
\cline { 2 - 4 } & Married & 68 & 45.3 \\
\cline { 2 - 4 } & Divorced & 16 & 10.7 \\
\hline & Employ & 49 & 32.6 \\
\cline { 2 - 4 } & Unemployed & 60 & 40 \\
\cline { 2 - 4 } & Retired & 31 & 20.6 \\
\cline { 2 - 4 } & Helpless & 10 & 6.6 \\
\hline
\end{tabular}




\begin{tabular}{|l|l|c|c|}
\hline General Information & Rating & Number & Percent \\
\hline \multirow{5}{*}{ Patients Education } & Notable read and write & 78 & 52.0 \\
\cline { 2 - 4 } & Able to read and write & 15 & 10.0 \\
\cline { 2 - 4 } & Primary & 22 & 14.7 \\
\cline { 2 - 4 } & Secondary & 12 & 8.0 \\
\cline { 2 - 4 } & Preparatory & 11 & 7.3 \\
\cline { 2 - 4 } & Institute and above & 12 & 8.0 \\
\hline
\end{tabular}

Out of 150 sample participated in the study were male married patients aged 30-39 years old unemployed and notable read and write.

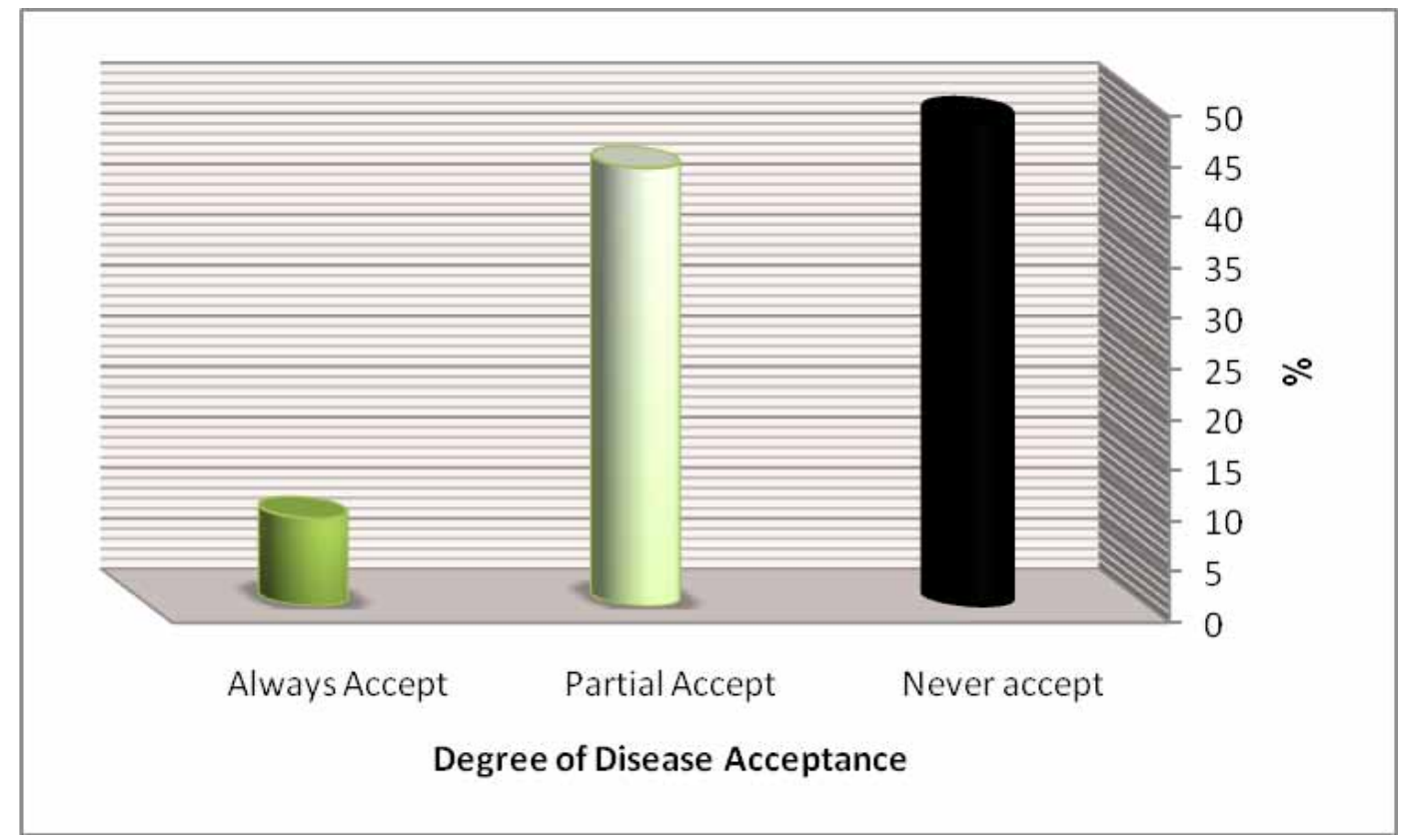

Figure 1. The Majority of Degree of Disease Acceptance

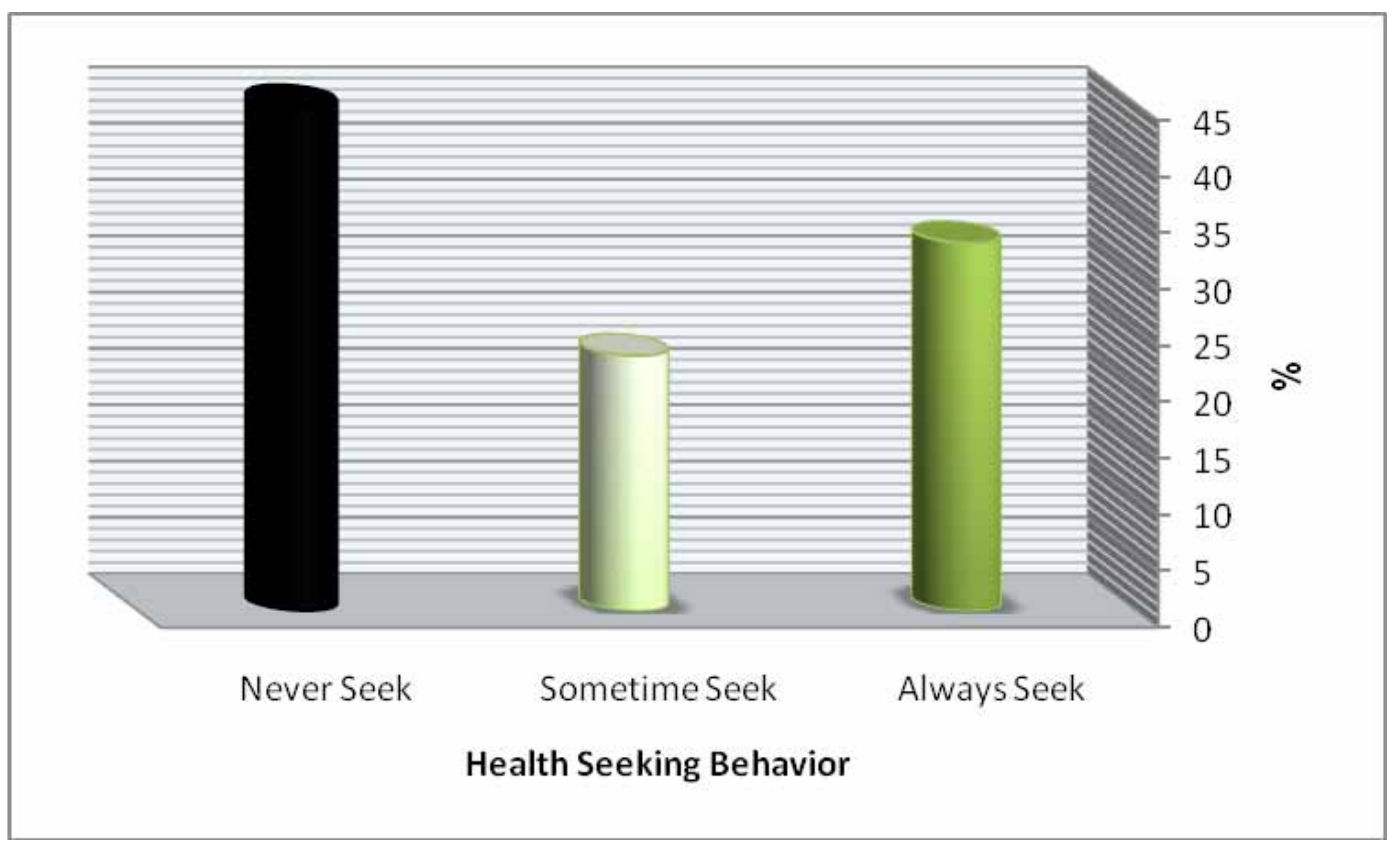

Figure 2: The Majority of Health Seeking 
Table 2. Statistical Relationship between Degree of Disease Acceptance and Seeking of Health Behavior

\begin{tabular}{|c|c|c|c|c|c|c|c|c|}
\hline \multirow{6}{*}{$\begin{array}{l}\text { Degree of Disease } \\
\text { Acceptance }\end{array}$} & \multirow{3}{*}{$\begin{array}{l}\text { Rate } \\
\text { Never Accept }\end{array}$} & \multicolumn{3}{|c|}{ Health Seeking } & \multirow{3}{*}{$\begin{array}{c}\text { Total } \\
72 \\
\end{array}$} & \multirow{2}{*}{ d.f. } & \multirow{2}{*}{\multicolumn{2}{|c|}{ Sig. }} \\
\hline & & \multirow{2}{*}{$\begin{array}{c}\text { Never Seek } \\
37 \\
\end{array}$} & \multirow{2}{*}{$\begin{array}{c}\text { Little Seek } \\
21 \\
\end{array}$} & \multirow{2}{*}{$\begin{array}{c}\text { Always Seek } \\
14 \\
\end{array}$} & & & & \\
\hline & & & & & & \multirow{4}{*}{4} & \multirow{4}{*}{$\begin{array}{l}\chi^{2} \text { obs. }=14.630 \\
\chi^{2} \text { crit. }=9.488 \\
\text { P-value }=.006\end{array}$} & \multirow{4}{*}{$\mathrm{S}$} \\
\hline & Partial Accept & 25 & 13 & 27 & 65 & & & \\
\hline & Always Accept & 5 & 0 & 8 & 13 & & & \\
\hline & Total & 67 & 34 & 49 & 150 & & & \\
\hline
\end{tabular}

" $\chi^{2}$ obs. $=$ Chi-square observer, " $\chi^{2}$ crit. $=$ Chi-square critical, $\mathrm{Df}=$ Degree of freedom, P-value $=$ Probability value, $\mathrm{S}=$ significant".

Findings presented there were a significant relationship between the degree of disease acceptance and seeking of health behavior at $\mathrm{p}$-value $<0.05$.

\section{Discussion}

Making sure that the diabetes diseases that need follow-up health program always satisfactory, Because type 2 diabetes is a chronic and common disease, it affects about $90-85 \%$ of the total diabetics, and the spread of this disease is alarmingly increasing, which constitutes a huge health burden on the individual, family and the state in terms of the costs of treatment and health followup. In 2000, the World Health Organization (WHO) noted that the number of people with diabetes is 171 million around the world, and that the frequency of its occurrence is increasing rapidly ${ }^{7}$.

Our findings depicts that most of the study sample aged (30-39) years old, (56.7\%) male, (45.3\%) married, (40\%) unemployed, and (52\%) notable read and write. This results consisting with field study of the Biskra and El Oued in order conducted to psychosocial rigidity and its relationship to acceptance of treatment in people with diabetes ${ }^{8}$.

In light of the percentage, out of the 150 patent, the majority ( $48 \%$ and $44.7 \%$ ) have never accepted their illness and seek about health, respectively. It involves not accepting treatment on several aspects, which causes the patient and the doctor several factors or problems between them, leading to the patient not feeling good, which is the basis for the success of the commitment to good treatment process. More importantly, it is the lack of attention to the patient and the doctor, and the doctor treating the patient as a case, and the level of information and understanding of the parties, and the inability to remember information by patients.

These results are consistent with the study assessed satisfaction of patients with the treatment of diabetes. Explained their findings that satisfaction with treatment lower among patients with diabetes, who are treated with insulin or suffering from diabetes complications and difficulties associated with the intake of drugs and Aotyon to follow-up visits. It concludes that the decision-makers and patients need to meet the specific needs of these patients may be effective in improving their satisfaction, and this has a positive effect on other clinical outcomes ${ }^{9}$.

As weakness depends on the presence of hardness on several factors, the most important (the lack of religious values system in patients who prevent them from falling into delinquency or illness or addiction, or the lack of goals in their lives, and the meanings they committed and their associates, lack of initiative, lack of leadership, not wanting to leadership, the inability to steadfastness and resistance, optimism and a positive attitude towards life, the inability to make decisions and choose between multiple alternatives, lack of calm and the ability to regulate and control the emotional exploitation ${ }^{10}$.

The belief that success in life is due to the work and the unknown, not luck or luck and circumstances, and not to take advantage of the experiences of selfdevelopment failure, most of them patients with diabetes do not feel good.

Characterized by the characteristics of people who do not seek at all to health for the loss of their sense of themselves, in the sense of their lives, and do not interact with their environment positively and expect the continued threat of weakness in the face of changing events, and prefer events that have no belief in the need for renewal and improvement stability, and negative in their interaction with the bad effects for stressful events and is capable of ${ }^{11}$.

Moreover, the psychological and social aspect 
requires such a measure, such as commitment and control (will) in patients with diabetes management, follow complex nutrition self-care, physical activity and glucose control in the blood and medicine recommendations. Compliance with these recommendations to improve control of blood sugar and reduce the risk of complications of diabetes. However, many patients are struggling to follow these behaviors in everyday life ${ }^{10}$.

In the relationship between the physician and the patient, self-care communication largely influenced by personal confidence. Doctors need to integrate the skills and personal relationships to establish a relationship of trust. Obstacles include the level of the doctor in front of communication on self-care time constraints, lack of cooperation and teamwork among health care providers, and the lack of patients' access to resources, and the lack of psycho-social support for patients with diabetes. Among patients, the psychological and social barriers that may affect the health literacy is ready to discuss selfcare. Motivational interviews are useful in improving communication methods ${ }^{12}$.

In the assessment of the relationship between the degree of acceptance of the disease and the pursuit of behavior towards health. We presented our findings and a great relationship between the degree of acceptance of the disease and the pursuit of health behavior at the value of $p<0.05$. The higher the degree of acceptance of the disease, increased control and the will and the commitment and the pursuit of health. These results consist of the results were evaluated psychological stress and its relationship with the acceptance of treatment in patients with diabetes. They have made clear their findings that the acceptance of a relationship or association solidly self-treatment because being selfstiffness means the will and commitment to tolerance and control of the treatment, because people who suffer from stiffness of moderate or low self do not accept treatment ${ }^{8}$.

\section{Conclusions}

Patients who diagnosed with type 2 diabetes and who review the diabetic center were never accepted their disease and never seek health. The accepted of disease were affected the seek towards health. Study that can be supported by a qualitative work using the clinical methodology with its tools and methods such as case study, clinical interview and psychological tests to achieve satisfactory acceptance and high self-control.
Financial Disclosure: There is no financial disclosure.

Conflict of Interest: None to declare.

Ethical Clearance: All experimental protocols were approved under the Kut Technical Institute, Middle Technical University, Iraq and all experiments were carried out in accordance with approved guidelines.

\section{References}

1. Mani N, Caiola E, Fortuna R. The influence of social networks on patients' attitudes toward type ii diabetes. J Community Health, 2011;36(40):728732.

2. Van DamH,van der Horst F, Knoops L, Ryckman R, Crebolder H, van den Borne B. Social support in diabetes: a systematic review of controlled intervention studies. Patient Educ Couns, 2015;59(21):1-12.

3. LowL, TongS, Low W. Mixed feelings about the diagnosis of type 2 diabetes mellitus: a consequence of adjusting to health related quality of life. Coll Antropol, 2014;38(29):11-20.

4. Gallant M. The influence of social support on chronic illness self-management: a review and directions for research. Health Educ Behav, 2013;30(55):170-195.

5. Stopford R, Winkley K, Ismail K. Social support and glycemic control in type 2 diabetes: a systematic review of observational studies. Patient Educ Couns, 2013;93(81):549-558.

6. Mayberry L, Osborn C. Family support, medication adherence, and glycemic control among adults with type 2 diabetes. Diabetes Care, $2012 ;(61) 35: 1239$ 1245.

7. WildS, Raglic G, green A, Sucrée R, King H. global prevalence of diabetes: estimates for the year 2000 and projections for 2030. diabetes care, 2004;30(27):1047-1053.

8. Erythematosus N. psychosocial rigidity and its relationship to acceptance of treatment in people with diabetes: A Field Study in the Basketry and Valley. Supplementary note to the Master's Degree in Psychology, Ayadi, 2015;96(11):110-117.

9. Biderman A, Noff E, Harris S, Friedman N, Levy A. Treatment satisfaction of diabetic patients: what are the contributing factors?. Family Practice-An International Journal, 2009;10(10):102-108. 
10. Nada A. Psychological Rigidity and its Relationship to the Stress of Life among Azhar University students in Gaza. Master Thesis, Azhar University in Gaza, Faculty of Education, Department of Psychology, 2007;139(92):192-288.

11. Nofal Z. Hardness of the Mothers of Martyrs of the AL-Aqsa Intifada and its Relation to Some
Variables", Master Thesis, Islamic University, Gaza, 2008;87(21): 232-239.

12. Beverly A, Worley F, Court B, Prokopakis E, Ivanov N. Patient-Physician Communication and Diabetes Self-Care. Clinical Communication, 2016; 23(11): 509-518. 